\title{
Utilization of Lime for Stabilizing Soft Clay Soil of high organic content
}

\author{
Mohamed A. Sakr ${ }^{1}$, Mohamed A. Shahin ${ }^{2, *}$ and Yasser M. Metwally \\ ${ }^{1}$ Associate Professor, Department of Structural Engineering, Tanta University, Egypt \\ ${ }^{2}$ Lecturer, Department of Civil Engineering, Curtin University of Technology, WA, Australia \\ ${ }^{3} \mathrm{PhD}$ Candidate, School of Geology and Geophysics, University of Oklahoma, USA
}

\begin{abstract}
This paper presents the results of geotechnical and mineralogical investigations on lime-treated soft clay soil from Idku City, Egypt, where high organic matters of about $14 \%$ exist. Lime was added in the order of $1,3,5$ and $7 \%$ by weight and laboratory experiments after 7, 15, 30 and 60 days were conducted including the mineralogical and microstructural examinations, grain size analysis, plasticity limits, unconfined compressive tests, vane shear tests and oedometer tests. The results indicate that soft clay soil of high organic content of $14 \%$ can be stabilized satisfactorily with the addition of $7 \%$ lime. The results also demonstrate that the changes in the mineralogical contents and soil fabric of high organic lime-treated soft clay improve soil plasticity, strength and compressibility.
\end{abstract}

Key words: soft clay, lime stabilisation, organic matters, cementing agents, pozzolanic reactions.

\section{Introduction}

Clay soils are commonly stiff in dry state but lose their hardness when saturated with water. Soft clays are characterized by low bearing capacity and high

\footnotetext{
* Corresponding author: Mohamed Shahin, Department of Civil Engineering, Curtin University of Technology, WA 6845, Australia. Phone: +61 89266 1822; Fax: +61 89266 2681; E-mail: m.shahin@ curtin.edu.au
} 
compressibility. The reduction in strength and stiffness of soft clays causes bearing capacity failure and excessive settlement, leading to severe damage to buildings and foundations. In Egypt, soft clays are widely distributed in the Central and Northern parts of the Nile Delta, where they range in thickness from less than one meter to more than $15 \mathrm{~m}$. The soft clays in this region are generally brown to dark gray in color and are characterized by the abundance of organic matter of about $14 \%$ and high water content of $60-90 \%$. They are also normally underlain by medium to coarse sand with gravel bed or sometimes peat soils, and overlain by medium to stiff clay soils.

In many places in the Nile Delta, particularly in the Northern part, soft clay soils cause irregular inclination of superstructures and severe damage to infrastructures. In view of this, several methods may be applied to improve the engineering characteristics of soil so that the stability and serviceability requirements can be met. As mentioned by McDowell (1959), soil stabilization for construction purposes, especially for earth roads, has a very long history in ancient Egypt. Among available methods of soil stabilization is the addition of common chemical admixtures such as lime, cement and flyash.

In the present work, lime stabilization of soft clay soils from Idku City, Egypt, where many buildings suffered severe differential settlements, was utilized. Special feature of Idku City clay is the high content of organic matters. Generally speaking, the stabilization behaviour of mixing soil with lime can be attributed to the flocculation of clay particles that aggregate together to form larger size particles, or to create new cementing materials due to the pozzolanic reactions of lime with the clay minerals (Narasimha and Rajasekaren, 1996). As investigated by Sabry (1977), many significant 
engineering properties of soft soils can be beneficially modified by lime treatment as lime decreases the plasticity index, increases the workability and shrinkage limit, reduces shrinkage cracking, eliminates almost all swelling problems, increases the California Bearing Ratio (CBR) and soil strength as well as increases permeability of soils. In addition, lime can be extended at deep in-situ level either in the form of lime column or lime injection (Okumura and Terashi, 1975).

\section{Experimental Program}

Several mineralogical and geotechnical experiments were carried out on limestabilized soft clay samples of high organic matters, before and after treatment. The materials used and the tests conducted are described and discussed below.

\subsection{MATERIALS}

The soil used in the present study is a natural soft clay soil obtained from Idku City, Egypt (Figure 1). The soft clay at Idku City starts at 1 to $3 \mathrm{~m}$ depth under the ground surface and extends down to about $15 \mathrm{~m}$. The soft clay in this region is generally overlain by a very fine silty sand (about $30 \mathrm{~m} \mathrm{~mm}$ thick) and underlain by a layer of medium to coarse sand. Sufficient amount of clay samples, weighing about $50 \mathrm{~kg}$ each, was obtained at $3 \mathrm{~m}$ depth using an open pit, and was transferred to laboratory for experiments. Extreme precautions were taken during sampling to keep the clay in its natural water conditions. The clay obtained was brown to dark gray in color and was characterized by a high content of organic matters of about $14 \%$. The grain size 
distribution of the soil used is shown in Figure 2. The lime used was a fine ground calcium hydroxide $\mathrm{Ca} \mathrm{OH}_{2}$ provided by a local company.

\subsection{TREATMENT PROCEDURE}

In this work, a number of 16 specimens from the natural clay samples were investigated. Lime was added to each specimen at the room temperature $\left(25 \pm^{\circ} \mathrm{C}\right)$ in the order of $1,3,5$ and $7 \%$ by weight. The lime was thoroughly mixed by hand until homogeneity was reached, and the mixture was quickly stored in a large plastic bag to prevent losing of moisture content. All lime-treated soil specimens were tested after curing time of $7,15,30$ and 60 days.

\subsection{MINERALOGICAL AND MICROSTRUCTURAL TESTS}

The mineralogy and microstructure of the clay and non-clay minerals of the soil used was identified by the X-ray diffraction technique (XRD) and scanning electron microscope (SEM). Semi quantitative estimation of clay minerals was based on peak areas, and on peak height for non-clay minerals, as proposed by Pierce and Siegel (1969).

\subsection{GEOTECHNICAL TESTS}

The geotechnical experiments conducted in the present study include the grain size analysis, plasticity limits, unconfined compressive tests, vane shear tests and oedometer tests. For untreated and treated soils, the grain size analysis was performed on the sandsize fractions of soil (larger than $0.063 \mathrm{~mm}$ ) using the procedure proposed by Folk 
(1974), and for particles less than $0.063 \mathrm{~mm}$, a hydrometer type $152-\mathrm{H}$ was used according to ASTM D422 (1990). In the hydrometer test, the oragnic matter was removed using $20 \%$ hydrogen peroxide $\left(\mathrm{H}_{2} \mathrm{O}_{2}\right)$, while $4 \%$ sodium hexamataphosphate (Calgon, $\mathrm{NaPO}_{3}$ ) was used as diepersing agent.

The plasticity limits (i.e. liquid limit, $L L$, and plastic limit, $P L$ ) were conducted in accordance with the ASTM D4318 (1984). The unconfined compressive strength, $q_{u}$, was determined using the unconfined compression apparatus on soil specimens of fixed dimensions of $38 \mathrm{~mm}$ diameter and $76 \mathrm{~mm}$ height, as described by Bowles (1992). The undrained shear strength, $c_{u}$, was obtained from the value of $q_{u}$ and also using the vane shear strength apparatus according to the Egyptian Code of Practice (1993).

The consolidation behavior was determined by an oedometer apparatus in accordance with Bowles (1992) using specimens of fixed dimensions of $21.5 \mathrm{~mm}$ in height and $71.3 \mathrm{~mm}$ in diameter. The soil compressions in each specimen used were recorded at applied vertical pressures of $25,50,100,200$ and $400 \mathrm{kPa}$, and at the time intervals recommended by Casagrande (1936).

\section{Results and Discussions}

\subsection{MINERALOGICAL AND MICROSTRUCTURAL ANALYSIS}

In this part, the results of XRD and SEM on the soil used are briefly presented. Detailed description of XRD and SEM conducted in this work is given elsewhere (Saker and Metwally 2000). The results of XRD on the untreated soil specimens indicated that 
kaolinite, illite and smectite were the principal clay minerals of the soil sediment. Other non-clay minerals were also detected in the bulk samples which include quartz, feldspar, halite and calcite. XRD of the lime-treated soil illustrated that a relative decrease in peak intensities of kaolinite, illite and smectite was observed with increasing lime percent. This is attributed to the pozzolanic reactions of lime with these minerals, leading to the destruction of their structure. Meanwhile, kaolinite showed less rate of decreased relative peak intensity with increasing lime content than those of illite and smectite, which can be attributed to the relative stability of kaolinite compared with illite and smectite.

SEM indicated that lime attacked the soil minerals and reacted with them forming new cementing materials. As observed by the results of XRD, these new compounds were calcite, nekolite, yugawaralite, calcium silicate hydrates of the form $\mathrm{CSH}_{2}$, calcium aluminate hydrates of the form $\mathrm{CAH}_{10}$ and $\mathrm{C}_{3} \mathrm{AH}_{6}$. These new materials usually occupy the intergranular soil voids or sometimes coat the soil particles, resulting in a decrease in soil porosity and permeability, depending on the lime content.

\subsection{GEOTECHNICAL ANALYSIS}

\subsubsection{Grain size distribution}

The grain size distribution of untreated (natural) soil samples from Idku City has indicated that the soil is compsed of $13 \%$ sand, $29.6 \%$ silt and $57.4 \%$ clay, which can be classified, according to Folk (1974), as sandy mud. With the addition of lime, an increase in the sand-size particles was observed with the increase of lime percent and 
curing time (Figure 3a). This increase in sand-size particles is due to the aggregation of silt- to sand-size particles as a result of formation of cementing materials by possolanic reactions of lime with soil. Figure $3 \mathrm{~b}$ shows that silt-size particles behave differently, as they increase during the first 15 days of lime treatment, then decraese with the increase of curing time. The initial increase of silt-size particles (for curing time up to 15 days) is attributed to the aggregation of clay-size particles, while the following decrease in silt-size particles (for curing time $>15$ days) is probably due to either the partial aggregation of silt- to sand-size particles or the deaggregation of silt- to clay-size particles.

\subsubsection{Plasticity limits}

The untreated soil specimens reflected a high plasticity values possibly due to the high content of organic matters and fine grained materials. According to the Unified Soil Classification System (USCS), the soil used can be classified as OH (organic clay of medium to high plasticity). After treatment with lime for several days (i.e. 7, 15, 30 and 60 days), the liquid limit, $L L$, of trated soil increases with lime percent, but at decreasing amounts with the number of days (Figure 4a). This is attributed to the hygroscopic effect (i.e. adsorption of intergranular water from soil), which is gradually decreasing with time due to pozzolanic reactions. On the other hand, for icreased lime content of 1,3,5 and 7\%, LL decreases with the increase of curing time (Figure 4b). This is probably due to the substitution of $\mathrm{Ca}$ ions with $\mathrm{Na}$ and $\mathrm{K}$ ions in the clay minerals, causing a reduction in soil water content, as explained by Hilt and Davidson (1961). Meanwhile, the behavior of plastic limit, $P L$, is similar to that of $L L$ but with 
different rates (Figure 5). Accordingly, the plasticity index (plascticty index $=L L-P L$ ) is decreasing with lime percent and increasing with curing time.

\subsubsection{Shear strength}

The unconfined compressive strength, $q_{u}$, of untreated clay was estimated to be around $10 \mathrm{kPa}$, which indicates a very soft soil. Figure 6 shows that the stress-starin curves of untreated soils exhibit a continuous deformation until a steady state is reached, with no true failure points are observed. This is in agreement with the behavior of normally consolidated soils, which do not exhibit a pronounced stress-starin peaks. Figure 6 also shows that the stress-strain curves of lime-treated soils exhibit a gradual pronounced peaks, depending on the lime percent and curing time, which is attributed to the cementation of soil particles due to pozzolanic reactions, as mentioned earlier. It can also be seen from Figure 6 that the lime fixation point of treated soil is about $3 \%$, as this is the lime percent where the behavior of treated soil changes from soft to stiff. This behavior has led to an increase in $q_{u}$ with the increase of lime percent and curing time (Figure 7a). For example, with the addition of $7 \%$ lime, an improvement in $q_{u}$ of about 330 and $660 \%$ were achieved after curing time of 7 and 60 days, respectively. Meanwhile, Figures $(7 \mathrm{~b}, \mathrm{c})$ show that both the stress-strain elastic modulus, $E_{s}$, and soil undrained cohesion, $c_{u}$, increase with the increase of lime content and curing time.

\subsubsection{Consolidation tests}

The consolidation behavior was investigated by studying the changes in the initial void ratio, $e_{o}$, compression index, $C_{c}$, preconsolidation pressure, $P_{c}$, and coefficient of 
consolidation, $C_{v}$, for a number of oedometer tests on untreated and $1 \%$ lime-treated soil specimens. It should be noted that the focuss of this study is to investigate the primary consolidation rather than the secondary conolidation (creep), as the influence of secondary consolidation for chamically stabilised soft soils should not be inmportant, as mentioned by Locat et al. (1996). Figure 8 shows the consolidation curves of the specimens used from which $e_{o}$ and $C_{c}$ of untreated and $1 \%$ treated soils at different curing times are obtained and depicted in Figure 9. It can be seen from Figure 9a that the initial void ratio, $e_{o}$, of treated soil increases at the beginning of curing time until it reaches a maximum value at 7 days, then decreases with the increase of curing time. The initial increase in void ratio (for curing time up to 7 days) is attributed to the hydration reaction between lime and water entraped in the structure of clay minerals, which is diminished with the consumption of lime during reaction with clay minerals. The following decrease in void ratio (for curing time $>7$ days) is probably due to the variation of grain size of lime-treated soil.

The consolidation behaviour of clay soil was expressed in terms of the compression index, $C_{c}$, and preconsolidation pressure, $P_{c}$, which were obtained from the consolidation curves of Figure 8 . It can be seen from Figure $9 \mathrm{~b}$ that $C_{c}$ increases at the first 15 days, indicating more compressible behaviour, then decreases with more curing time. The initial increase in $C_{c}$ (for curing time up to 15 days) is attributed to the consumption of water from the clay minerals that bonds the clay sheets, while the following increase in $C_{c}$ (for curing time > 15 days) is related to the formation of pozzolanic compounds and new cementing materials. It can aslo be seen from Figure $9 \mathrm{c}$ that $P_{c}$, which is normally developed due to the inter-particle cementing bonds, were found to decrease with the increase of curing time to 15 days, and then increase with the 
increase of curing time. The initial decrease in $P_{c}$ (for curing time up to 15 days) is attributed to the consumption of water from the clay minerals that bonds the clay sheets, while the following increase in $P_{c}$ (for curing time $>15$ days) is related to the formation of pozzolanic compounds and new cementing materials. In general, Figure 9 shows that the gain in soil strength (or resistance to compression) is not significant at $1 \%$ lime even after 60 days. This is in agreement with Locat et al. (1996), who found that the gain in strength of treated soil with less than $2 \%$ lime is much less significant than that of higher lime concentrations, and that the effect of curing time are more distinct for lime concentration greater than $2 \%$.

The variation of the coefficient of consolidation, $C_{v}$, with the change in curing time was also investigated at different applied pressures. In general, it was found that the values $C_{v}$ of lime-treated samples were greater than those of untreated samples, indicating improvement of lime-treated soil.

\subsubsection{Hydraulic conductivity}

The hydraulic conductivity of soil was estimated by the coefficient of permeability, $k$, from the results of the consolidation tests on $1 \%$ lime-trated soil and was derived using the modified Darcy's law. The results are given in Figure 10, which show that $k$ of the lime-treated samples increases with curing time until it reaches a maximum value after 15 days and decreases after that time. The increase in $k$ is attributed to the increase in sand and silt fractions while the decrease in $k$ is probably related to the growth of cementing materials the fill the interparticles porosity. 


\section{Statistical Analysis of Test Results}

A multiple regression analysis was carried out to obtain the relationships that correlate the geotechnical properties of lime-treated soils (i.e. liquid limit, $L L$; plastic limit, $P L$; unconfined compressivs strength, $q_{u}$; modulus of elasticity, $E_{s}$; and cohesion, $c$ ) with the curing time $(t)$ and lime content $(L C)$. The following equations were derived:

$L L(\%)=95.63+1.23 L C(\%)-0.11 t($ days $)$

$P L(\%)=63.76+3.62 L C(\%)-0.44 t($ days $)$

$q_{u}(k P a)=6.28+8.68 L C(\%)+0.47 t($ days $)$

$E_{s}(M P a)=-0.31+0.25 L C(\%)+0.02 t($ days $)$

$c(k P a)=2.54+4.37 L C(\%)+0.24 t($ days $)$

Strong cofficients of correlation $(r)$ between the measured and predicted values using the above equations were obtained and found to be equal to: $0.93,0.95,0.91,0.90$ and 0.91 for $L L, P L, q_{u}, E_{s}$ and $c$, respectively. The above equations are useful in the sense that they give a quick guide to the characteristics of lime-treated soft clay soils of high organic matters. 


\section{Summary and Conclusions}

The results of geotechnical and mineralogical investigation on lime-treated soft clay soils from Idku City, Egypt, were investigated and discussed. Lime was added in the order of 1, 3, 5 and $7 \%$ by weight and experiments after 7, 15, 30 and 60 days were conducted. Relationships that correlate the geotechnical properties of lime-treated soils were developed. The study has led to the following conclusions reagrding lime-treated soil fo high organic content:

1. Several constituents of caly minerals can be affected by the addition of lime, leading to development of new cementing minerals and other compounds such as calcite, nekolite, calcium silicate hydrates $(\mathrm{CSH})$ and calcium aluminate hydrates $(\mathrm{CAH})$.

2. There is a gradual increase in grain size of treated soil with increasing lime percent, depending on curing time. This is not an increase in particle sizes, but it is due to the formation of soil lumps.

3. There is an increase in both liquid and plastic limits of soil with lime addition, but they decrease with curing time.

4. The unconfined compressive strength of soil can be increased by nearly seven times by the addition of $7 \%$ lime after curing time of 60 days. In addition, a remarkable improvement in both mudulos of elascticty and soil cohesion can be achived by the adition of lime, depending on the curing time. 
5. The lime fixation point occurs at $3 \%$ lime addition where the behavior of soil changes from soft to stiff.

6. The compressibility of $1 \%$ lime-treated does not show a significant improvement in soil compressibility, howver, it is expected that soil compressibility can be gradually improved with the increase of lime percent.

7. Overall, the research reported in this study proves that soft Idky clay can be stabilized satisfactorily with the addition of about $7 \%$ lime. 


\section{References}

ASTM D422 (1990) Standard test methods for particle size analysis of soils, Annual Books of ASTM Standards.

ASTM D4318 (1984) Standard test method for liquid limit, plastic limit and plasticity idex of soil, Annual Books of ASTM Standards.

Bowles, J. E. (1992) Engineering properties of soils and their measurements, McGrawHill, Inc., New York.

Casagrande, A. (1936). The determination of the pre-consolidation load and its practical significance, In: Proceedings, 1st International Conference on Soil Mechanics and Foundation Engineering, Massachusetts, 60-64.

Egyptian Code of Practice (1993) Soil mechanics and design of foundations. Part I: Site investigation, Ministry of Housing and Utilities, Cairo, Egypt.

Folk, R. L. (1974) Petrology of sedimentary rocks, Hemphills, Austin, Texas.

Hilt, G. H. and Davidson, D. T. (1961) Isolation and investigation of a limemontmorillonite crystalline reaction product, Highway Research Board, Record No. 304, 51-64.

Locat, J. Tremblay, H. and Leroueil, S. (1996) Mechanical and hydraulic behaviour of a soft inorganic clay treated with lime, Canadian geotechnical Journal, 33(4), 654-669.

McDowell, C. (1959) Stabilization of soils with lime, lime-flyash and other lime reactive materials, Highway Research Board, 231, 60-66.

Narasimha, R. S. and Rajasekaren, G. (1996) Reaction products formed in lime stabilisation marine clays, Journal of Geotechnical Engineering, 122(5), 329336. 
Okumura, T. and Terashi, M. (1975) Deep lime mixing method of stabilisation for marine clays, Proceedings, 5th Asian Regional Conference of Soil Mechanics and foundation Engineering, 1, 69-75.

Pierce, J. W. and Siegel, F. R. (1969) Quantification in clay mineral studies of sediments and sedimentary rock, Journal of Sedimentary Petrology, 9, 187-193.

Sabry, M. A. (1977). Mineralogical and engineering properties of compacted soil lime mixture, $\mathrm{PhD}$ thesis, Oklahama State University, Oklahama.

Sakr, M. A. and Metwally, Y. M. (2000). Lime treatment of soft clay soils from Idku City, Egypt - engineering and geological approach, In: Proceedings, 4th International Geotechnical Engineering Conference, Cairo University, Cairo, Egypt, 685-700. 


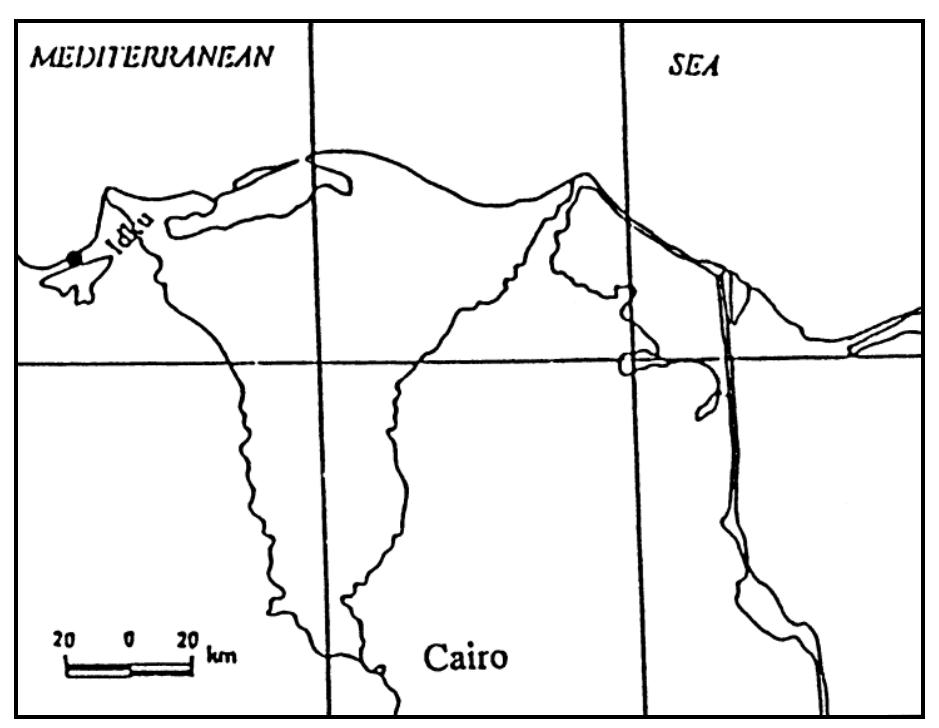

Figure 1. Location map of the study area

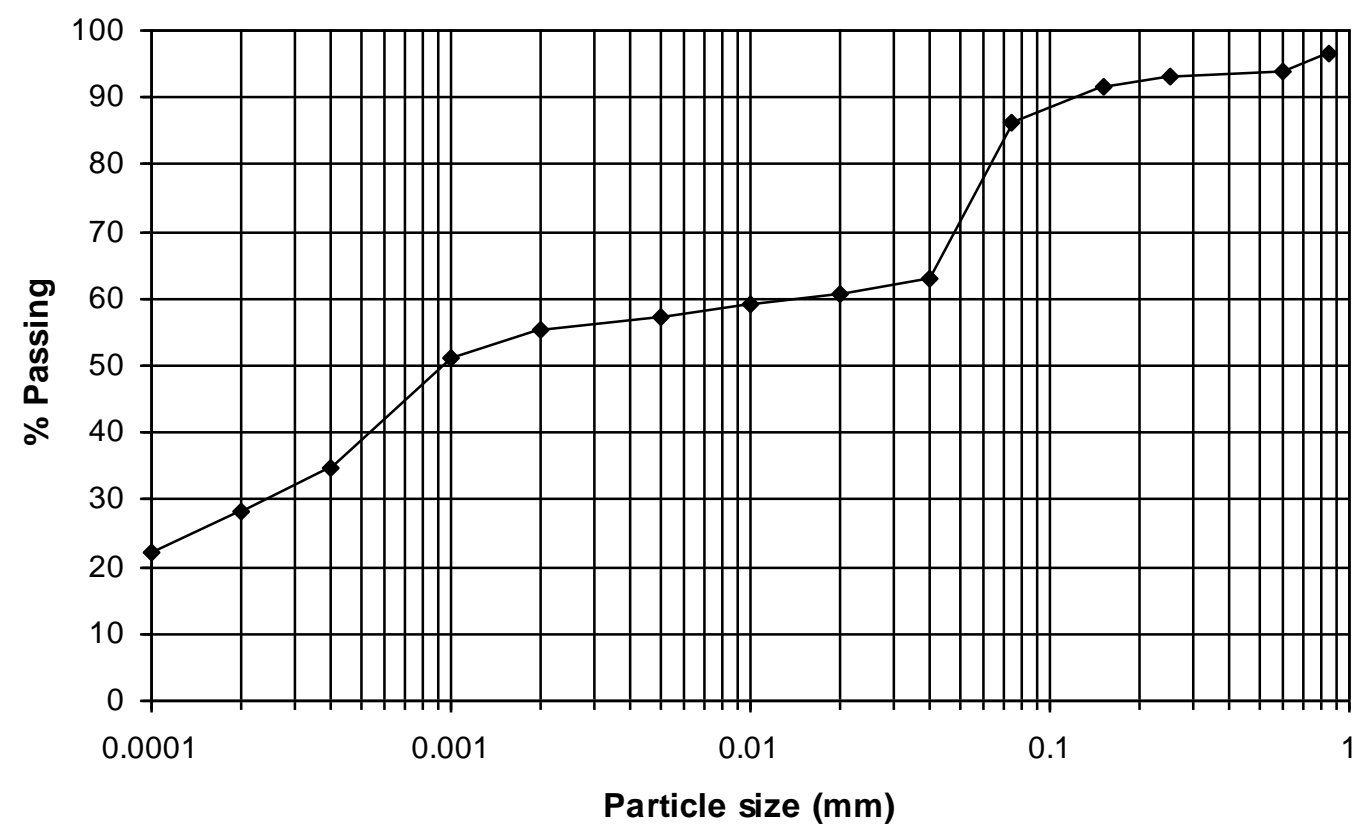

Figure 2. Grain size distribution of soft Idku clay 

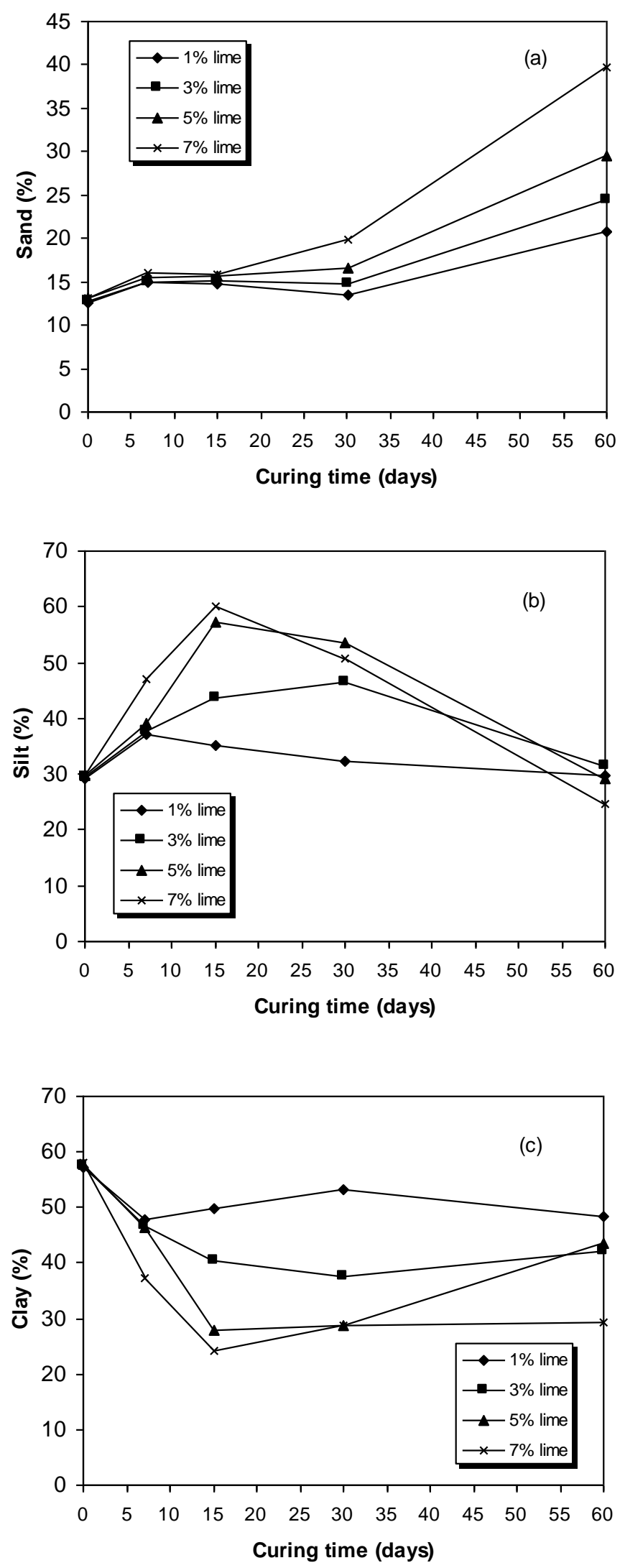

Figure 3. Percentage of : (a) sand; (b) silt and (c) clay, on lime-treated soil 

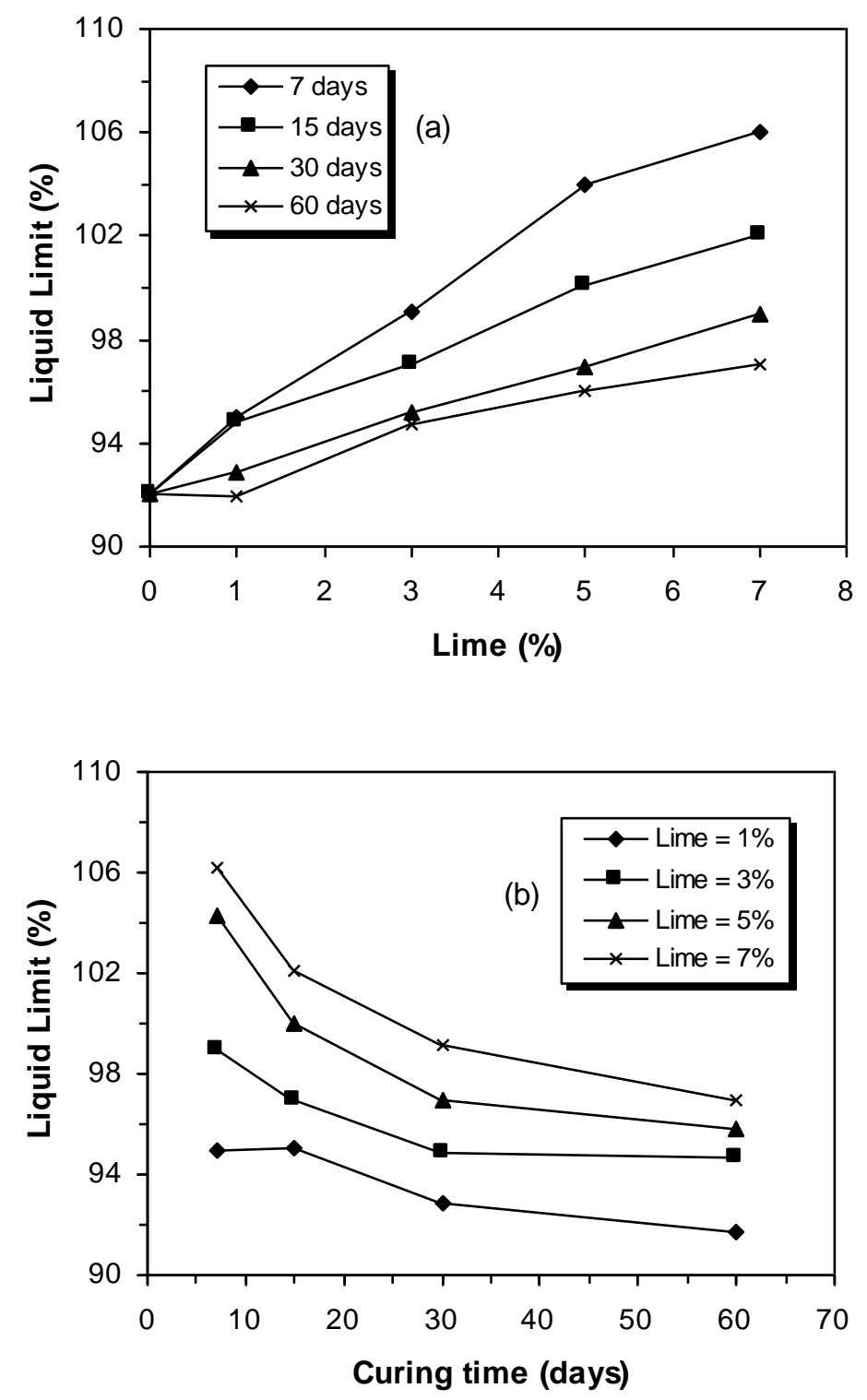

Figure 4. Relationships of liquid limit of lime-treated soil with: (a) lime percent and (b) curing time 

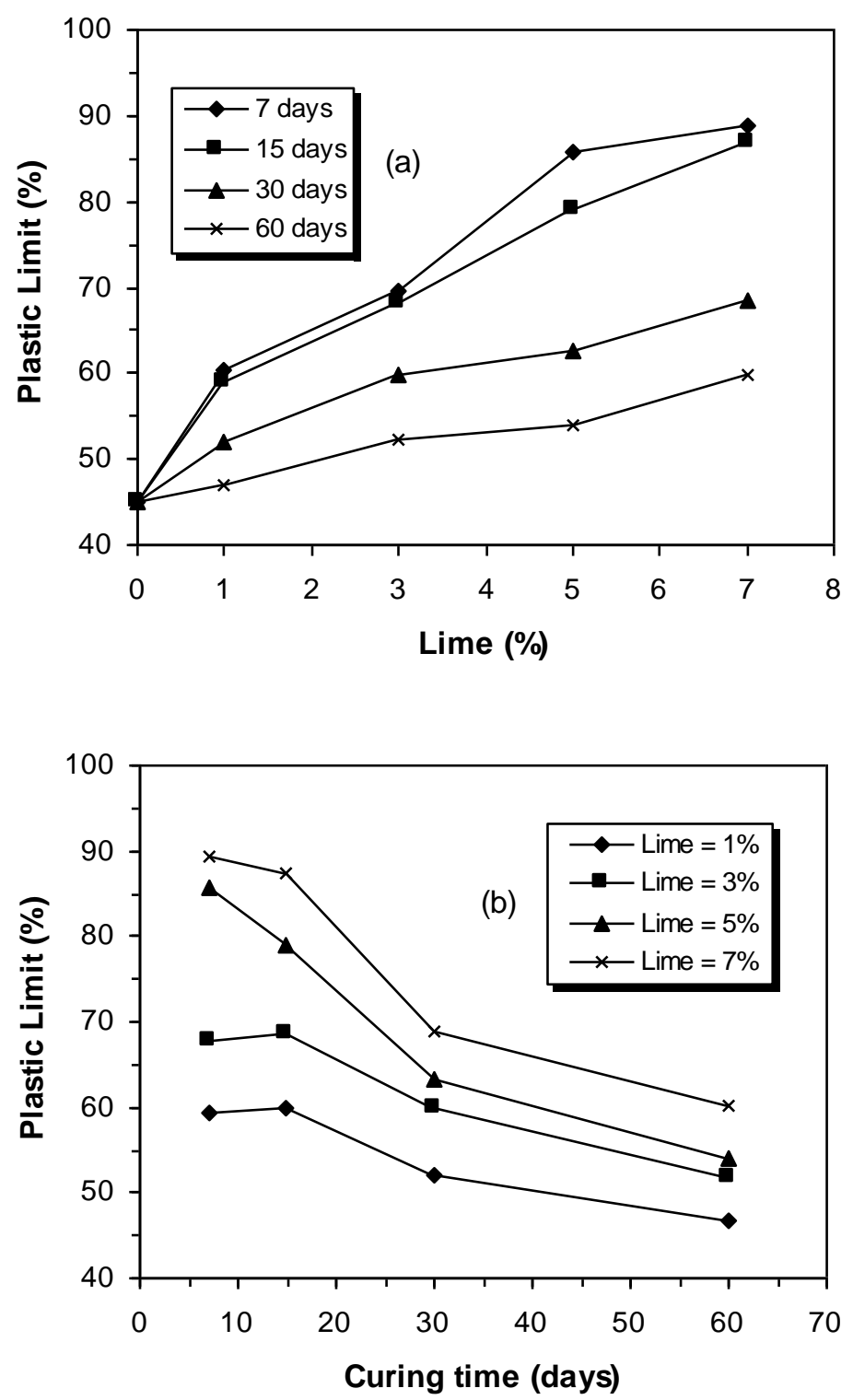

Figure 5. Relationships of plastic limit of lime-treated soil with: (a) lime percent and (b) curing time 

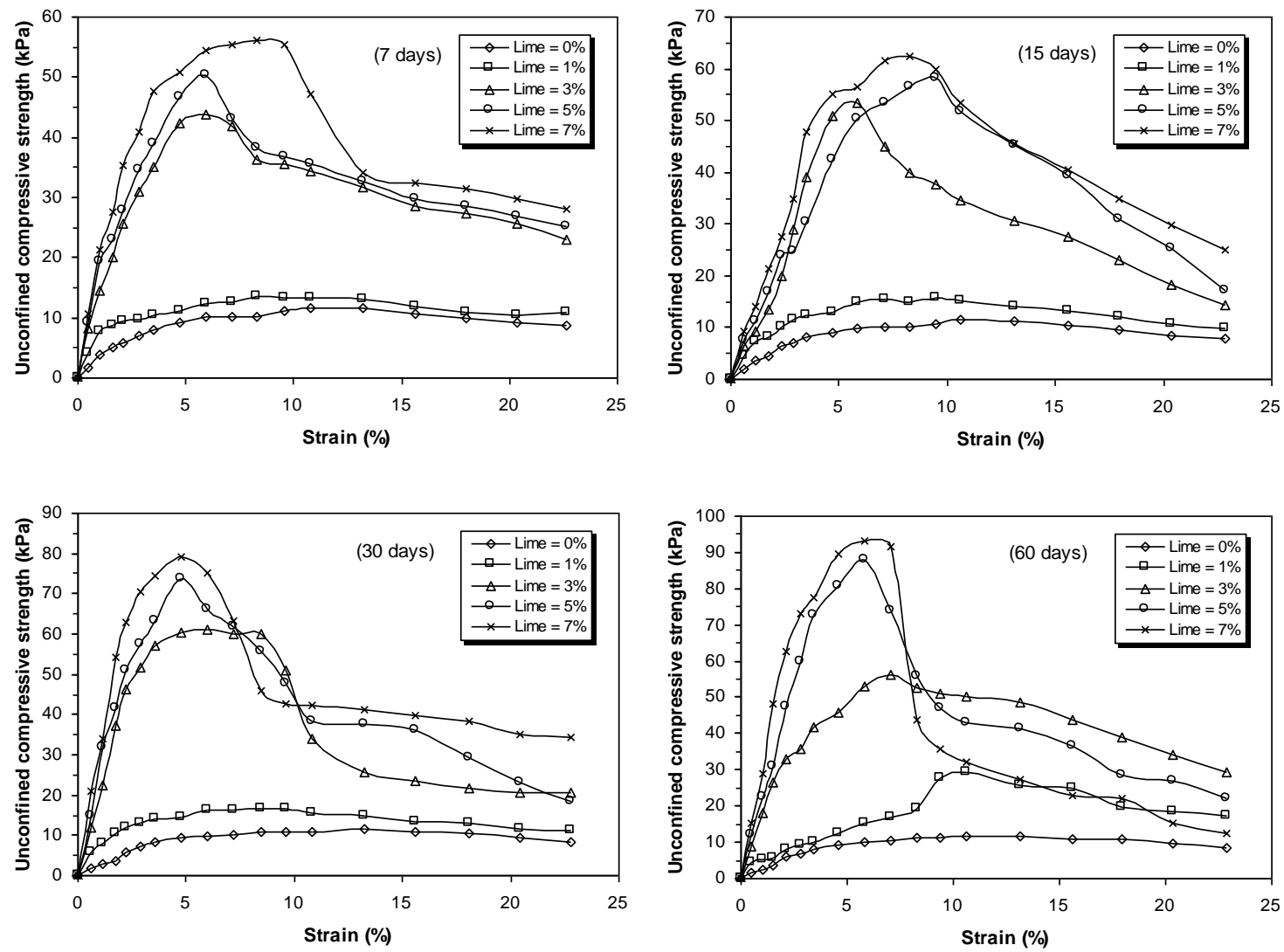

Figure 6. Stress-strain curves of untreated and lime-treated soft clays 

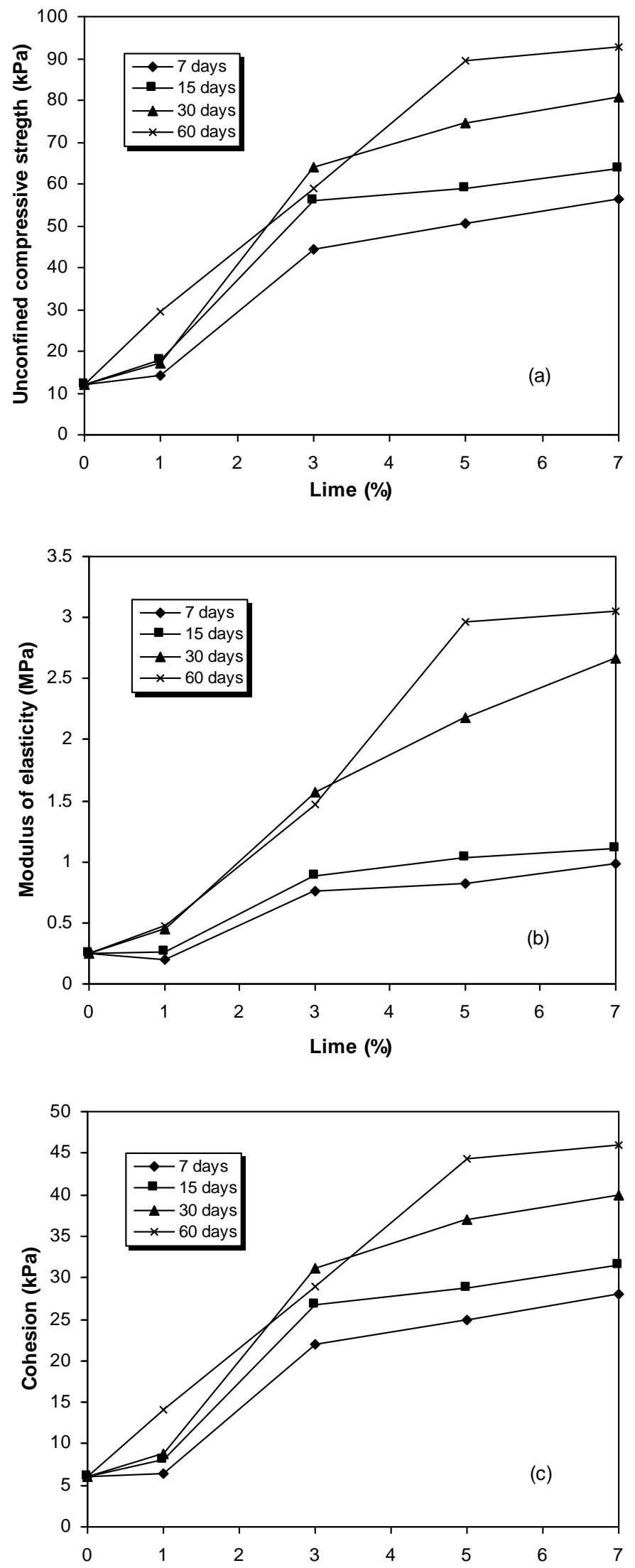

Figure 7. Effects of lime percent on: (a) unconfined compressive strength; (b) stress-strain modulus of elasticity and (c) soil undrained cohesion 


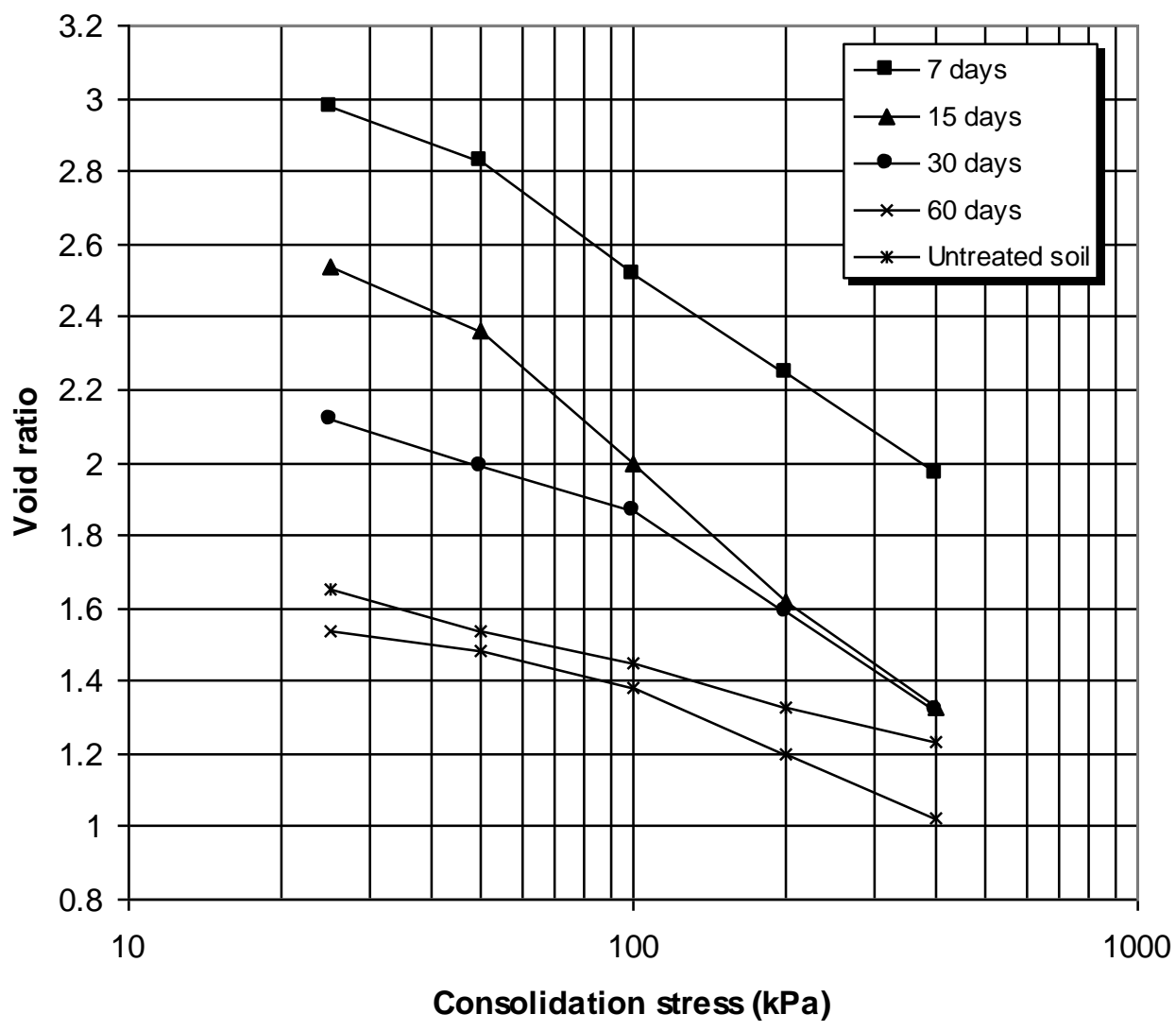

Figure 8. Consolidation curves for untreated and $1 \%$ lime treated soils 

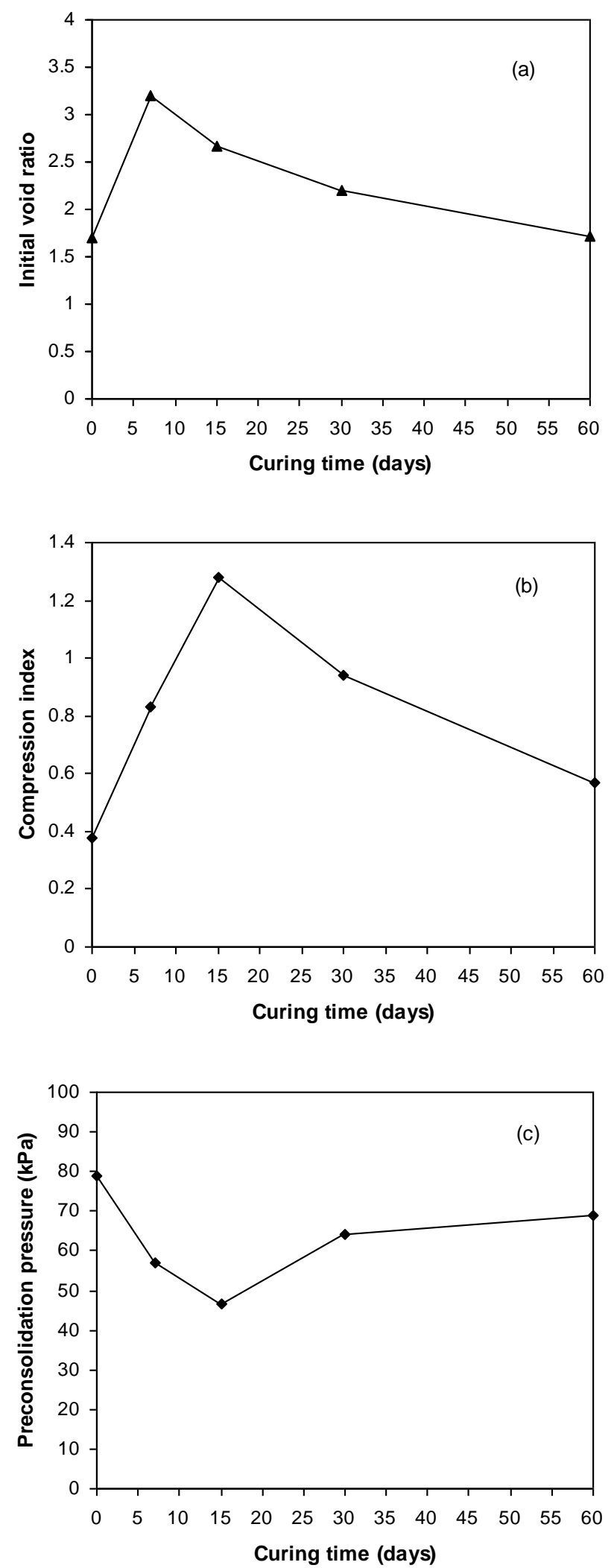

Figure 9. Effects of curing time on: (a) initial void ratio and (b) compression index at $1 \%$ lime 


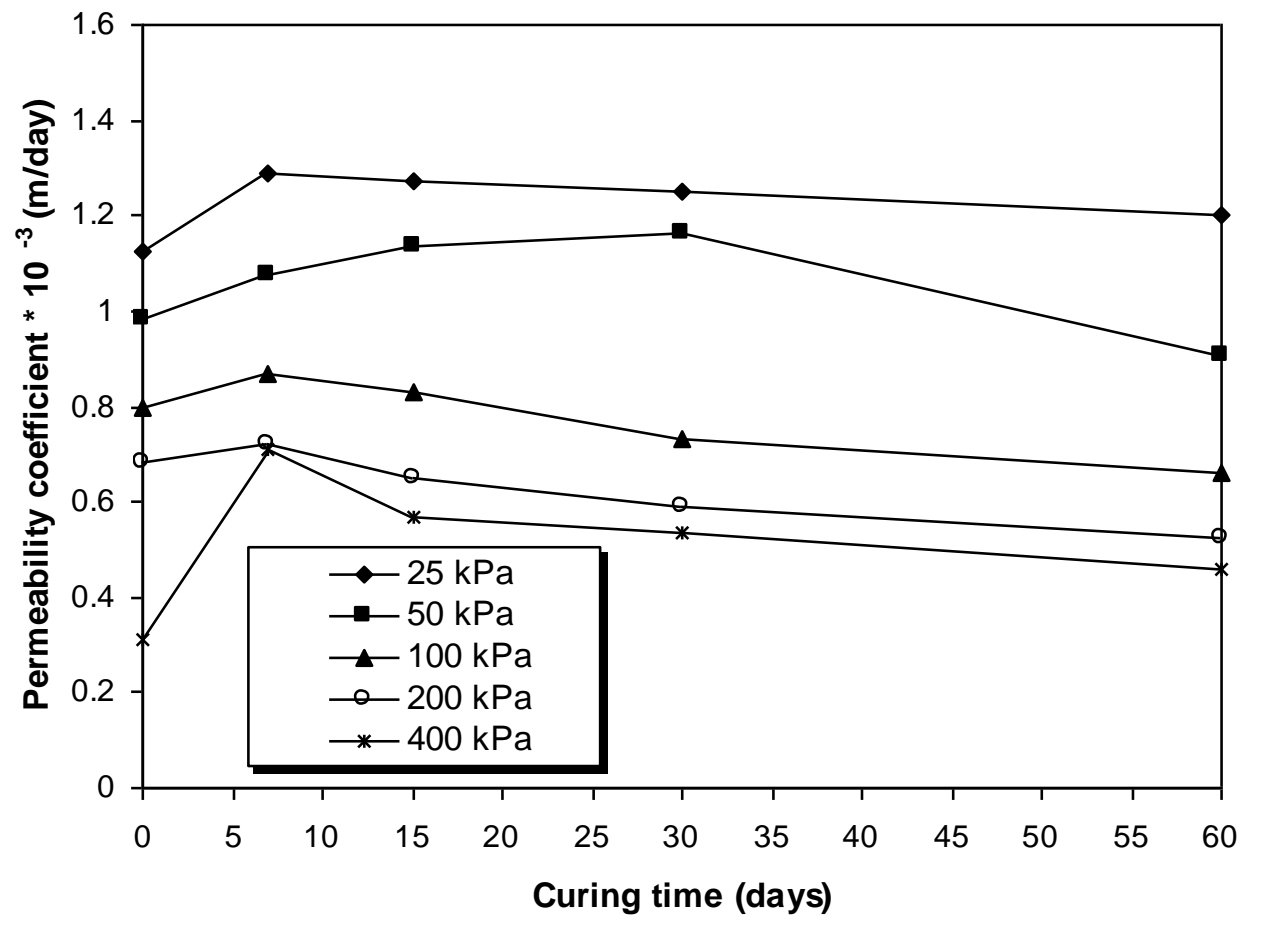

Figure 10. Relationship between permeability of treated soil and curing time at $1 \%$ lime 